\title{
Predictors of autopsy following stillbirth in Queensland, Australia: a population
} based study

\author{
Ibinabo IBIEBELE ${ }^{1,2}$ \\ Frances M BOYLE ${ }^{1,2}$ \\ Dell HOREY ${ }^{1,3}$ \\ Rohan LOURIE ${ }^{1,4}$ \\ Patricia WILSON ${ }^{5}$ \\ Michael COORY ${ }^{6,7}$ \\ Vicki FLENADY ${ }^{1,2}$
}

${ }^{1}$ Mater Research Institute-University of Queensland, Brisbane, Australia

${ }^{2}$ School of Public Health, University of Queensland, Brisbane, Australia

${ }^{3}$ Department of Public Health, La Trobe University, Melbourne, Australia

${ }^{4}$ Translational Research Institute, Brisbane, Australia

${ }^{5}$ Mater Mothers' Hospital, Mater Health Services, Brisbane, Australia

${ }^{6}$ Murdoch Childrens Research Institute, Melbourne, Australia

${ }^{7}$ Department of Paediatrics, University of Melbourne, Melbourne, Australia

Address for correspondence

Level 2 Aubigny Place, Raymond Terrace,

South Brisbane, Queensland, 4101, Australia

Tel: $+61731632555 \quad$ Fax: +61731632550

Email: Ibinabo.Ibiebele@uqconnect.edu.au

\section{Predictors of stillbirth autopsy in Queensland (short title)} article as doi: 10.1111/ajo.12563

This article is protected by copyright. All rights reserved 
Word Count: 250 (abstract) 2513 (main text)

\section{$\underline{\text { Acknowledgements }}$}

Ibinabo Ibiebele is a recipient of the National Health and Medical Research Council Postgraduate Public Health scholarship and the University of Queensland Research scholarship. Rohan Lourie is a recipient of the Betty McGrath/Mater Practitioner Research Fellowship.

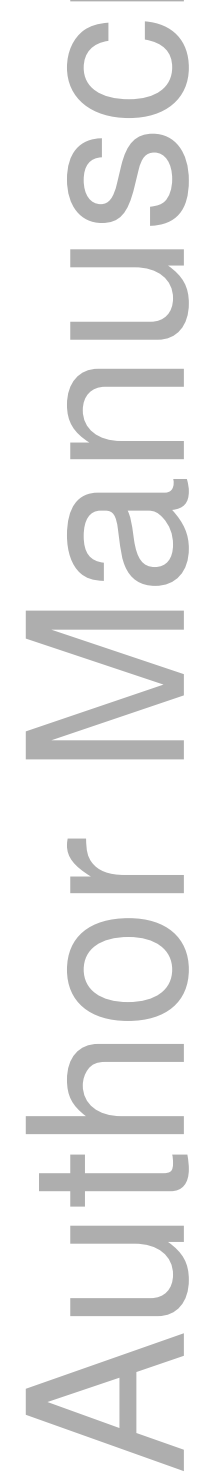


Received Date : 04-Apr-2016

Revised Date : 21-Aug-2016

Accepted Date : 03-Oct-2016

Article type : Original Manuscript

Predictors of autopsy following stillbirth in Queensland, Australia: a population based study

Short Title: Predictors of stillbirth autopsy in Queensland

Word Count: 227 (abstract), 2394 (main)

Tables: Two

Keywords: stillbirth, fetal death, autopsy, gestational age

\section{Abstract}

Background: Accurate determination of causes of stillbirth is critical to effective prevention. Autopsy remains the gold standard investigation for stillbirth, however with low autopsy rates; many stillbirths are likely to be "unexplored" rather than "unexplained".

Aim: To determine factors associated with autopsy following stillbirth.

Materials and methods: Routinely collected population-based data on all singleton stillbirths of at least $400 \mathrm{~g}$ birthweight or 20 weeks gestation in Queensland between July 2000 and December 2011 were examined. Adjusted odds ratios [aOR, 99\%CI] were calculated accounting for sociodemographic, pregnancy and medical factors. Of interest was initially unexplained stillbirth on the death certificate; analysis was stratified by gestational age group $(<24,24-27,28-36$ and $\geq 37$ weeks $)$.

Results: Of 3842 singleton stillbirths included in these analyses, $1356(35.3 \%)$ had an autopsy performed. Initially unexplained stillbirth was associated with decreased odds of 
autopsy at late gestation (28-36 weeks, aOR 0.63 [99\% CI 0.42,0.93]; $\geq 37$ weeks, aOR 0.53 [99\% CI 0.35,0.81]) as was intrapartum stillbirth (<24 weeks, aOR 0.63[99\%CI 0.43,0.94]; 28-36 weeks, aOR 0.37 [99\%CI 0.14-0.98]) ). Congenital abnormality ( $<24$ weeks, $\geq 37$ weeks), small-for-gestational age ( $<24$ weeks), and primigravidity ( $\geq 37$ weeks) were associated with increased odds of autopsy following stillbirth.

Conclusions: Pregnancy factors are associated with stillbirth autopsy. These findings have implications for development of appropriate information for parents and education of clinical staff. Further research is needed into factors influencing autopsy following stillbirth.

\section{Introduction}

Stillbirth is a devastating pregnancy outcome for women and families across the world. Many high income countries like Australia have witnessed little improvement in stillbirth rates for several decades ${ }^{1,2}$. Furthermore, within many high income countries, Indigenous and minority groups often have higher risk of stillbirth ${ }^{2,3}$. A large proportion of stillbirths are unexplained $^{2}$; although the reported proportion of unexplained stillbirths varies with the classification system used ${ }^{4,5}$. Nevertheless, accurate information on the cause of death is necessary to inform effective prevention strategies.

Since thorough post mortem investigation reveals a cause of death in a substantial number of stillbirths of unknown clinical cause, it has been argued that many stillbirths are underinvestigated rather than unexplained ${ }^{2,6,7}$. Autopsy remains the gold standard examination for investigating stillbirth ${ }^{8}$, but steady declines in autopsy rates are well documented in Australia and other high income countries ${ }^{9}$. These declines contribute to the failure to improve in this area. We need to better understand the factors associated with autopsy following stillbirth to counter the decline in autopsy rates. Queensland stillbirth autopsy rates are around $37 \%{ }^{3}$, a figure well below the recommended rate of $75 \%{ }^{10}$. The objective of this study was to determine the maternal and pregnancy factors associated with autopsy following stillbirth in a high income setting.

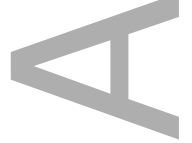

\section{Materials and methods}

We undertook a population-based cross sectional study involving all singleton stillbirths in Queensland of at least 20 weeks gestation or 400 grams birthweight occurring between July 
2000 and December 2011. Stillbirths resulting from terminations of pregnancy for maternal psychosocial reasons were excluded as factors affecting decisions for autopsy may differ within this group. Similarly analysis was restricted to singleton stillbirths because of differences in the type and distribution of cause of death which may influence autopsy rates ${ }^{11}$. Data for this study were obtained from the Queensland Perinatal Data Collection (QPDC), a statewide registry capturing information on all registered births in Queensland.

This dataset included maternal demographic, pregnancy, medical information and birth outcomes. Maternal demographic information included: age, Indigenous status, region of birth, marital status, socioeconomic status and geographic location. Indigenous status was determined from maternal self-reporting as Australian Aboriginal or Torres Strait Islander or not. The latter two demographic factors were derived from maternal residential postcode. Socioeconomic status was derived by mapping postcodes to the Australian Bureau of Statistics Index of relative socioeconomic disadvantage, a measure ranking geographic areas according to social and economic wellbeing ${ }^{12}$. Likewise, geographic location was derived by mapping postcodes to the Australian Standard Geographic Classification (ASGC) Remoteness structure, a measure of physical distance to the nearest urban centre ${ }^{13}$. Pregnancy and medical data included: gravidity, hospital accommodation status (public, private), smoking, substance use, assisted conception use, diabetes (pre-existing and gestational), hypertensive disorders (pre-existing, pregnancy-induced and preeclampsia/eclampsia) and antepartum haemorrhage. Birth outcome data included: congenital abnormality, small-for-gestational age (defined as birthweight less than $10^{\text {th }}$ Australian population percentile for gestational age, sex and plurality), gestational age at birth, diagnosis of unexplained stillbirth on the death certificate, and type of stillbirth (antepartum, intrapartum and unknown if antepartum or intrapartum). All variables were treated as categorical.

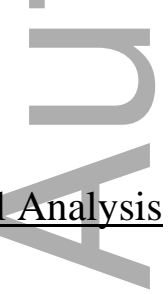

The primary outcome measure was autopsy following stillbirth (either full or partial). Differences in characteristics between births where an autopsy was performed following stillbirth and those where it was not were assessed using Chi square test. Unadjusted association between characteristics and autopsy was explored using univariate logistic 
regression. Significant interactions were found between gestational age and initially unexplained fetal death as well as between gestational age and the presence of a congenital abnormality. Multivariate analysis was undertaken including all predictors with a significant univariate association with stillbirth autopsy as well as other important maternal characteristics. Analysis was stratified by gestational age group $(<24,24-27,28-36$ and $\geq 37$ weeks), although this was not specified a priori. A significance level of $p<0.01$ was set due to multiple comparisons.

Statistical analysis was performed using Stata/SE for Windows 13.1 (StataCorp LP, College Station, TX, USA). Ethics approval was obtained from the Queensland Health Central Office (Ref: HREC/05/QHC/009), University of Queensland School of Population Health (Ref: II180313) and Mater Health Services (Ref: HREC/15/MHS/36/AM07) Human Research Ethics Committees.

\section{Results}

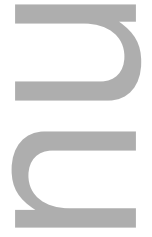

A total of 3,842 women with a singleton stillbirth between July 2000 and December 2011 were included in these analyses. Of these women, 1356 (35.3\%) had an autopsy performed for their stillborn infant. The triennial autopsy rate ranged from $28.3 \%$ to $38.4 \%$ during the study period. There was no statistically significant change in overall autopsy rates over the study period, although rates increased by $9 \%$ per annum among stillbirths of 24-27 weeks $\left(\mathrm{p}_{\text {trend }}<0.01\right)$.

The characteristics of the study cohort by autopsy status are given in Table 1. Women who had a stillbirth where an autopsy was performed were more likely to be primigravid, have a small-for-gestational age infant or an infant with a congenital abnormality than women who did not. They were less likely to be Indigenous, experience antepartum haemorrhage, deliver at less than 24 weeks, have an initially unexplained stillbirth or an intrapartum stillbirth (Table 1).

\section{$\underline{\text { Stillbirths }<24 \text { weeks gestation }}$}

Among those with a stillbirth in the less than 24 week gestational age group, stillbirths that were small-for-gestational age (aOR 1.50, [99\% CI 1.06,2.11]) or had a congenital abnormality (aOR 1.62 [99\% CI 1.12,2.35]) were more likely to have an autopsy performed. 
Type of stillbirth was associated with decreased odds of having an autopsy in this group: intrapartum stillbirth (aOR 0.63, [99\% CI 0.43,0.94]) and stillbirths where it was unknown if they were antepartum or intrapartum (aOR 0.60, [99\% CI 0.39-0.91]) (Table 2).

\section{Stillbirths 24-27 weeks gestation}

Among those with a stillbirth in the 24-27 week gestational age group, there were increased odds of autopsy for stillbirth among women with a small-for-gestational age infant (aOR 1.55, [99\% CI 0.90,2.67]), However the result did not reach statistical significance.

Conversely, autopsy was less likely for stillbirths where it was unknown if the stillbirth was antepartum or intrapartum (aOR 0.23, [99\% CI 0.05,0.78]) (Table 2).

\section{Stillbirths 28-36 weeks gestation}

Women who had an intrapartum stillbirth (aOR 0.37, [99\% CI 0.14,0.98]) or an initially unexplained stillbirth (aOR 0.63, [99\% CI 0.42,0.93]) were less likely to have had an autopsy for their baby (Table 2).
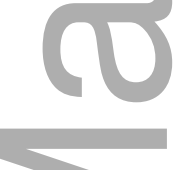

$\underline{\text { Stillbirths } \geq 37 \text { weeks gestation }}$

Among those women who had term stillbirths, primigravidity (aOR 1.74, [99\% CI 1.13,2.68]) and the presence of a congenital abnormality (aOR 2.90, [99\% CI 1.61,5.22]) were associated with increased odds of having an autopsy performed following stillbirth. In contrast, initially unexplained stillbirth (aOR 0.53, [99\% CI 0.35,0.1]) was associated with decreased odds of autopsy (Table 2).

\section{Discussion}

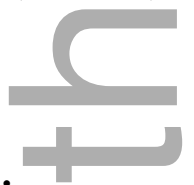

This population study found various pregnancy factors were associated with autopsy post stillbirth and that associations varied with gestational age.

It was a paradoxical finding that stillbirths occurring in late gestation (at 28 weeks gestation or more) that were unexplained at the time of completing the death certificate and prior to many stillbirth investigations being completed, were less likely to have an autopsy. The reason for this is not immediately clear. We were unable to determine which investigations 
besides autopsy were conducted. However, among stillbirths that were described as unexplained on the death certificate, the leading categories after subsequent investigation and classification were: unexplained antepartum fetal death (55.8\%), spontaneous preterm (11.7\%), antepartum haemorrhage (9.0\%) and fetal growth restriction (5.5\%). Classification to the latter three categories was less likely to rely on autopsy findings ${ }^{4}$. Furthermore, these findings may reflect barriers to autopsy consent that have been observed in surveys of health care professionals' view and practices, these include gaps in knowledge and training ${ }^{2}$ and an underestimation of the value of autopsy ${ }^{14}$. More broadly, an attitude of fatalism or "these things happen" is prevalent in relation to stillbirth ${ }^{2,15}$ and combined with the message from some healthcare providers that the autopsy may not reveal an explanation for the cause of death ${ }^{16}$ may deter parents who are faced with this difficult decision.

We found intrapartum stillbirth was associated with decreased odds of autopsy for preterm stillbirths. These findings are in accordance with a qualitative study which showed that parents were more likely to have an autopsy for antepartum stillbirth than intrapartum stillbirth $^{17}$. These findings may reflect the importance of having time to separate the autopsy decision from the immediate shock of the baby's death. Further analysis of these preterm intrapartum stillbirths showed that the leading categories of stillbirth were: congenital abnormality (44.3\%), spontaneous preterm (34\%) and antepartum haemorrhage (8.0\%). Apart from congenital abnormality, classification to the latter two categories depend largely on information from clinical history ${ }^{4}$.

Although not statistically significant after adjustment for pregnancy factors, we found Indigenous women were less likely to have an autopsy for their stillborn baby. These findings are particularly important as Indigenous women have higher rates ${ }^{1,3}$ and risk ${ }^{18}$ of stillbirth, as well as higher rates of unexplained stillbirth ${ }^{3}$. There is limited research into the views and experiences of Indigenous parents and families following stillbirth or cultural perceptions of stillbirth, and further research into the underlying factors affecting decision making is needed. The presence of antepartum haemorrhage was associated with decreased odds of autopsy for stillbirths occurring at 24 weeks or more gestation, though not statistically significant. This may reflect the ability of clinicians to discern cause of death from maternal clinical history and presentation in such instances ${ }^{4,19}$; and that post mortem examination may not necessarily provide much additional information. 
The presence of congenital abnormality was associated with increased odds of autopsy, in stillbirths occurring at 20-23 weeks gestation and at term ( $\geq 37$ weeks). This finding may reflect the value of autopsy to determine or confirm the cause of death in stillbirths where the suspected cause of death is congenital abnormality ${ }^{20,21}$. Antenatal diagnosis of congenital abnormality is likely to have involved multiple consultations between parents, families and specialists with development of trust. Rapport with the health care provider is important for seeking autopsy consent ${ }^{4}$. Clinicians may be motivated to seek consent as a result of interest in "interesting cases" or to confirm antenatal diagnosis.

We found increased odds of autopsy associated with small-for-gestational age (SGA) for stillbirths occurring at less than 24 weeks. SGA is a proxy measure for fetal growth restriction which is an important risk factor for stillbirth ${ }^{22}$. It is determined from biometric measurements at autopsy or antenatal ultrasound evidence of growth restriction after excluding infection and congenital abnormality which are associated with $\mathrm{SGA}^{4}$. A subset of pregnancies with SGA may have been monitored intensively and parents would have been informed of the poor prognosis. Similar to preterm intrapartum stillbirths, these parents may have had more time to reach some degree of acceptance of the loss. Information from autopsy may assist in management of subsequent pregnancies as there is evidence of increased risk of SGA recurrence ${ }^{23}$

This study found primigravidity was associated with increased odds of autopsy where stillbirth occurred at term. This may reflect parents' concerns or need for reassurance about achieving a successful future pregnancy outcome. Autopsy results can assist in determining cause of death and inform management of future pregnancies ${ }^{4}$.

Perinatal autopsy has been shown to improve understanding of the cause of death in $20-86 \%$ of $\operatorname{cases}^{24}$; and placental histology provides information regarding cause of death in $52 \%$ of cases $^{25}$. However the quality of autopsy varies ${ }^{26}$; and improved quality of autopsy as well as reporting and interpretation was found when performed by a perinatal pathologist ${ }^{27,28}$. Furthermore, a significant barrier to improving the quality of information on cause of death is a shortage of perinatal pathologist ${ }^{2}$. It is unclear which clinical scenario results in the highest yield of information for autopsy following stillbirth. Nevertheless, autopsy together with placental examinations could contribute to decreasing the rate of unexplained stillbirths ${ }^{29}$. 
This large population study is to our knowledge the first study exploring the association between autopsy and maternal factors in a quantitative manner using population data within an Australian context. The main limitations of the study related to the use of routinely collected data. Whether or not autopsy was performed could have been used as a proxy measure to indicate parental consent for autopsy, as consent was required for autopsy. However this was problematic as data were unavailable for the proportion of parents who were approached for consent. Furthermore, there may be instances where consent was given but autopsy was not performed although we suspect this would have occurred in a very small number of cases with minimal effect on the study findings. In addition, it was not possible to evaluate the comprehensiveness of stillbirth investigations as data were unavailable on the other tests or investigations performed.

This study highlights the need for further research into the factors that drive parental decision-making among the subgroups identified, particularly for parents less likely to consent to autopsy. This study also emphasises the need to ensure parents are given appropriate counselling regarding stillbirth autopsy to ensure they make an informed decision which is best for them. The importance of clinician education about the value of autopsy and approaching parents for consent is also emphasised.

\section{Conclusion}

This population study confirms that pregnancy factors are associated with autopsy after stillbirth. The study findings can be used to inform the development of appropriate parentfocussed information resources as well as education of clinical staff. Of concern is the decreased likelihood of autopsy for unexplained stillbirths. Further research is needed to understand the various underlying factors influencing autopsy following stillbirth.

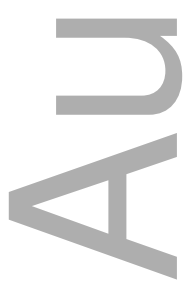




\section{References}

1. Hilder L, Li Z, Zeki R, Sullivan AE. Stillbirths in Australia, 1991-2009. Perinatal Statistics Series No. 29. Cat. no. PER 63. Canberra: AIHW National Perinatal Epidemiology and Statistics Unit, 2014.

2. Flenady V, Wojcieszek AM, Middleton P, et al. Stillbirths: recall to action in highincome countries. The Lancet 2016; 387(10019): 691-702.

3. Ibiebele I, Coory M, Boyle FM, Humphrey M, Vlack S, Flenady V. Stillbirth rates among Indigenous and non-Indigenous women in Queensland, Australia: is the gap closing? BJOG: An International Journal of Obstetrics \& Gynaecology 2015; 122(11): 1476-83.

4. Flenady F, King J, Charles A, et al. Clinical practice guideline for perinatal mortality. Version 2.2 April 2009. www.psanz.com.au. Brisbane, 2009.

5. Korteweg FJ, Gordijn SJ, Timmer A, Holm JP, Ravise JM, Erwich JJ. A placental cause of intra-uterine fetal death depends on the perinatal mortality classification system used. Placenta 2008; 29(1): 71-80.

6. Measey MA, Charles A, d'Espaignet ET, Harrison C, Deklerk N, Douglass C. Aetiology of stillbirth: unexplored is not unexplained. Aust N Z J Public Health 2007; 31(5): 444-9.

7. The Stillbirth Collaborative Research Network Writing Group. Causes of death among stillbirths. JAMA 2011; 306(22): 2459-68.

8. Ernst LM. A pathologist's perspective on the perinatal autopsy. Seminars in Perinatology 2015; 39(1): 55-63.

9. Stock SJ, Goldsmith L, Evans MJ, Laing IA. Interventions to improve rates of postmortem examination after stillbirth. Eur J Obstet Gynecol Reprod Biol 2010.

10. Royal College of Pathologists. Guidelines on autopsy practice: Report of a working group of the Royal College of Pathologists. 2002. http://www.rcpath.org/NR/rdonlyres/412AEB13-F5B8-4C6B-A0872833223C7A4D/0/main_document.pdf2004). 
11. Li Z, Zeki R, Hilder L, Sullivan AE. Australia's mothers and babies 2011. Perinatal statistics series no. 28. Cat. no. Per 59. Canberra: AIHW National Perinatal Epidemiology and Statistics Unit, 2013.

12. Australian Bureau of Statistics. An Introduction to Socio-Economic Indexes for Areas (SEIFA) 2006. ABS Cat. No. 2039.0. Canberra: ABS, 2008.

13. Australian Bureau of Statistics. Statistical Geography Volume 1 - Australian Standard Geographical Classification (ASGC). ABS Cat. No. 1216.0. Canberra: ABS, 2006.

14. Heazell AEP, McLaughlin MJ, Schmidt EB, et al. A difficult conversation? The views and experiences of parents and professionals on the consent process for perinatal postmortem after stillbirth. BJOG: An International Journal of Obstetrics \& Gynaecology 2012; 119(8): 987-97.

15. Frøen JF, Cacciatore J, McClure EM, et al. Stillbirths: why they matter. The Lancet 2011; 377(9774): 1353-66.

16. Cartlidge PH, Dawson AT, Stewart JH, Vujanic GM. Value and quality of perinatal and infant postmortem examinations: cohort analysis of 400 consecutive deaths. BMJ 1995; 310(6973): 155-8.

17. Meaney S, Gallagher S, Lutomski JE, O’ Donoghue K. Parental decision making around perinatal autopsy: a qualitative investigation. Health Expectations 2014.

18. Ibiebele I, Coory M, Smith GCS, et al. Gestational age specific stillbirth risk among Indigenous and non-Indigenous women in Queensland, Australia: a population based study. BMC Pregnancy and Childbirth 2016; 16: 159.

19. ACOG Practice Bulletin No. 102: management of stillbirth. Obstet Gynecol 2009; 113(3): 748-61.

20. Laing IA. Clinical aspects of neonatal death and autopsy. Semin Neonatol 2004; 9(4): 247-54.

21. Silver RM, Varner MW, Reddy U, et al. Work-up of stillbirth: a review of the evidence. Am J Obstet Gynecol 2007; 196(5): 433-44. 
22. Gardosi J, Madurasinghe V, Williams M, Malik A, Francis A. Maternal and fetal risk factors for stillbirth: population based study. BMJ 2013; 346.

23. Voskamp B, Kazemier B, Ravelli ACJ, Schaaf J, Mol BW, Pajkrt E. Recurrence of small-for-gestational-age pregnancy: analysis of first and subsequent singleton pregnancies in The Netherlands. Am J Obstet Gynecol 2013; 208: 374.e1-6.

24. Downe S, Kingdon C, Kennedy R, Norwell H, McLaughlin MJ, Heazell A. Postmortem examination after stillbirth: views of UK-based practitioners. European Journal of Obstetrics and Gynecology and Reproductive Biology 2012; 162(1): 33-7.

25. Bukowski R, Carpenter M, Conway D, et al. Causes of death among stillbirths. JAMA 2011; 306(22): 2459-68.

26. Vujanic GM, Cartlidge PH, Stewart JH, Dawson AJ. Perinatal and infant postmortem examinations: how well are we doing? J Clin Pathol 1995; 48(11): 998-1001.

27. Khong TY, Gordijn SJ. Quality of placental pathology reports. Pediatr Dev Pathol $2003 ; \mathbf{6}(1): 54-8$

28. Sun CC, Revell VO, Belli AJ, Viscardi RM. Discrepancy in pathologic diagnosis of placental lesions. Arch Pathol Lab Med 2002; 126(6): 706-9.

29. Bonetti LR, Ferrari P, Trani N, et al. The role of fetal autopsy and placental examination in the causes of fetal death: a retrospective study of 132 cases of stillbirths. Arch Gynecol Obstet 2011; 283(2): 231-41.

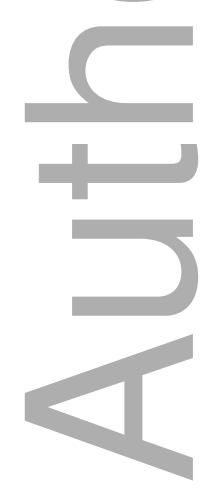


Table 1: Maternal and pregnancy characteristics by autopsy status for 3,842 women with a singleton stillbirth, Queensland, mid 2000-2011

\begin{tabular}{|c|c|c|c|}
\hline Characteristics & $\begin{array}{l}\text { Autopsy } \\
(n=1356)\end{array}$ & $\begin{array}{c}\text { No Autopsy } \\
(n=2486)\end{array}$ & $\begin{array}{c}\text { Unadjusted } \\
\text { Odds Ratio } \\
(95 \% \mathrm{CI})^{\S}\end{array}$ \\
\hline \multicolumn{4}{|l|}{ Maternal age } \\
\hline$\leq 18$ years & $39(2.9)$ & $71(2.9)$ & $1.03(0.69-1.55)$ \\
\hline $19-24$ years & $368(27.1)$ & $558(22.5)$ & $1.24(1.04-1.48)$ \\
\hline $25-30$ years & $422(31.1)$ & $794(31.9)$ & 1.00 (Reference) \\
\hline $31-34$ years & $279(20.6)$ & $489(19.7)$ & $1.07(0.89-1.30)$ \\
\hline $35+$ years & $248(18.3)$ & $574(23.1)$ & $0.81(0.67-0.98)$ \\
\hline Smoker & $204(15.0)$ & $375(15.1)$ & $0.89(0.73-1.08)$ \\
\hline Indigenous & $89(6.6)$ & $265(10.7)$ & $0.59(0.46-0.76)$ \\
\hline \multicolumn{4}{|l|}{ Maternal region of birth } \\
\hline Africa & $21(1.5)$ & $27(1.1)$ & $1.43(0.81-2.55)$ \\
\hline Americas and Caribbean & $13(1.0)$ & $20(0.8)$ & $1.20(0.59-2.42)$ \\
\hline Eastern Asia & $16(1.2)$ & $40(1.6)$ & $0.74(0.41-1.32)$ \\
\hline Central, South and West Asia & $22(1.6)$ & $36(1.4)$ & $1.13(0.66-1.92)$ \\
\hline South East Asia & $33(2.4)$ & $63(2.5)$ & $0.97(0.63-1.48)$ \\
\hline Europe & $63(4.6)$ & $81(3.3)$ & $1.43(1.02-2.01)$ \\
\hline Australia and New Zealand & $1164(85.8)$ & $2145(86.3)$ & 1.00 (Reference) \\
\hline Oceania & $20(1.5)$ & $68(2.7)$ & $0.54(0.33-0.90)$ \\
\hline \multicolumn{4}{|l|}{ Socioeconomic status } \\
\hline Highest ranked $20 \%$ & $174(12.8)$ & $270(10.9)$ & 1.00 (Reference) \\
\hline Middle ranked $60 \%$ & $926(68.3)$ & $1679(67.5)$ & $0.86(0.70-1.05)$ \\
\hline Lowest ranked $20 \%$ & $251(18.5)$ & $531(21.4)$ & $0.73(0.58-0.93)$ \\
\hline Substance Use & $28(2.1)$ & $38(1.5)$ & $1.36(0.83-2.22)$ \\
\hline Primiparity & $473(34.9)$ & $662(26.6)$ & $1.47(1.28-1.70)$ \\
\hline Assisted Conception & $51(3.8)$ & $96(3.9)$ & $0.97(0.69-1.38)$ \\
\hline Public patient & $1113(82.1)$ & $2020(81.3)$ & $1.05(0.89-1.25)$ \\
\hline Antepartum haemorrhage & $201(14.8)$ & $497(20.0)$ & $0.70(0.58-0.83)$ \\
\hline
\end{tabular}

This article is protected by copyright. All rights reserved 


\begin{tabular}{|c|c|c|c|}
\hline Characteristics & $\begin{array}{l}\text { Autopsy } \\
(n=1356)\end{array}$ & $\begin{array}{c}\text { No Autopsy } \\
(n=2 \text { 486) }\end{array}$ & $\begin{array}{c}\text { Unadjusted } \\
\text { Odds Ratio } \\
(95 \% \mathrm{CI})^{\S}\end{array}$ \\
\hline Pre-existing diabetes & $35(2.6)$ & $52(2.1)$ & $1.24(0.80-1.91)$ \\
\hline Gestational diabetes & $56(4.1)$ & $71(2.9)$ & $1.47(1.03-2.09)$ \\
\hline Pre-existing hypertension & $28(2.1)$ & $52(2.1)$ & $0.99(0.62-1.57)$ \\
\hline Pregnancy-induced hypertension & $34(2.5)$ & $39(1.6)$ & $1.61(1.01-2.57)$ \\
\hline Pre-eclampsia and Eclampsia & $58(4.3)$ & $82(3.3)$ & $1.31(0.93-1.85)$ \\
\hline \multicolumn{4}{|l|}{ Gestational age group } \\
\hline 20-23 weeks & $441(32.5)$ & $1106(44.5)$ & $0.56(0.47-0.67)$ \\
\hline $24-27$ weeks & $186(13.7)$ & $311(12.5)$ & $0.84(0.67-1.06)$ \\
\hline 28-36 weeks & $377(27.8)$ & $571(23.0)$ & $0.93(0.77-1.12)$ \\
\hline$\geq 37$ weeks & $348(25.7)$ & $490(19.7)$ & 1.00 (Reference) \\
\hline \multicolumn{4}{|l|}{ Gender } \\
\hline Female & $612(45.1)$ & $1171(47.1)$ & 1.00 (Reference) \\
\hline Male & $721(53.2)$ & $1284(51.6)$ & $1.07(0.94-1.23)$ \\
\hline Undetermined & $23(1.7)$ & $29(1.2)$ & $1.52(0.87-2.65)$ \\
\hline Small for gestational age & $460(33.9)$ & $716(28.8)$ & $1.28(1.11-1.48)$ \\
\hline Congenital abnormality & $483(35.6)$ & $741(29.8)$ & $1.30(1.13-1.50)$ \\
\hline Unexplained stillbirth $^{*}$ & $523(38.6)$ & $1071(43.1)$ & $0.83(0.72-0.95)$ \\
\hline \multicolumn{4}{|l|}{ Type of stillbirth } \\
\hline Antepartum & $1024(75.5)$ & $1574(63.3)$ & 1.00 (Reference) \\
\hline Intrapartum & $179(13.2)$ & $501(20.2)$ & $0.55(0.46-0.66)$ \\
\hline Unknown & $153(11.3)$ & $411(16.5)$ & $0.57(0.47-0.70)$ \\
\hline \multicolumn{4}{|l|}{ Geographic location } \\
\hline Major city & $803(59.2)$ & $1358(54.6)$ & 1.00 (Reference) \\
\hline Regional & $501(36.9)$ & $1009(40.6)$ & $0.84(0.73-0.96)$ \\
\hline Remote & $51(3.8)$ & $119(4.8)$ & $0.72(0.52-1.02)$ \\
\hline \multicolumn{4}{|l|}{ Epoch } \\
\hline $2000-2002$ & $282(20.8)$ & $452(18.2)$ & 1.00 (Reference) \\
\hline $2003-2005$ & $260(19.2)$ & $659(26.5)$ & $0.63(0.51-0.78)$ \\
\hline 2006-2008 & $378(27.9)$ & $674(27.1)$ & $0.90(0.74-1.09)$ \\
\hline
\end{tabular}

This article is protected by copyright. All rights reserved 


\begin{tabular}{cccc}
\hline Characteristics & $\begin{array}{c}\text { Autopsy } \\
(\mathbf{n = 1 ~ 3 5 6 )}\end{array}$ & $\begin{array}{c}\text { No Autopsy } \\
(\mathbf{n = 2} \text { 486) }\end{array}$ & $\begin{array}{c}\text { Unadjusted } \\
\text { Odds Ratio } \\
(\mathbf{9 5 \%} \text { CI })^{\S}\end{array}$ \\
\hline $2009-2011$ & $436(32.2)$ & $701(28.2)$ & $1.00(0.82-1.21)$ \\
\hline
\end{tabular}

${ }^{\dagger}$ Data on maternal smoking collected from mid 2005 onwards.

$\$$ Stillbirth unexplained on death certificate (ICD10AM code: P95)

$\S$ Odds of autopsy relative to no autopsy

Percentages may add up to greater than $100 \%$ due to rounding.
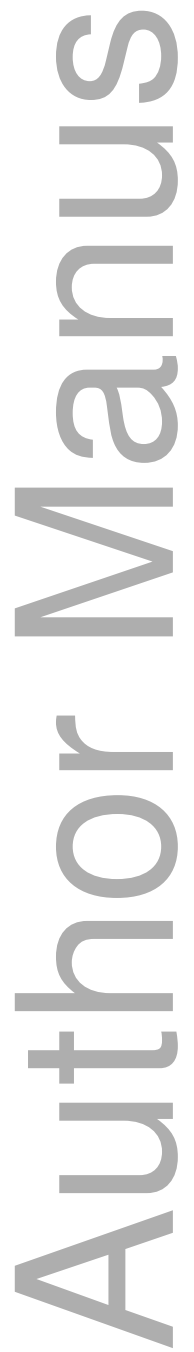

This article is protected by copyright. All rights reserved 
Table 2: Maternal and pregnancy factors associated with stillbirth autopsy, Queensland, mid 2000-2011

\begin{tabular}{|c|c|c|c|c|}
\hline \multirow[b]{2}{*}{ Characteristics } & \multicolumn{4}{|c|}{ Adjusted odds ratios $\left(99 \%\right.$ confidence interval) ${ }^{\S}$} \\
\hline & $\begin{array}{c}<24 \text { weeks } \\
(n=1547)\end{array}$ & $\begin{array}{c}\text { 24-27 weeks } \\
\qquad(n=497)\end{array}$ & $\begin{array}{c}\text { 28-36 weeks } \\
\qquad(n=948)\end{array}$ & $\begin{array}{c}\geq 37 \text { weeks } \\
\quad(n=838)\end{array}$ \\
\hline \multicolumn{5}{|c|}{ Maternal Age (Reference: 25-30 years) } \\
\hline$\leq 18$ year & $1.28(0.46-3.58)$ & $0.63(0.12-3.30)$ & $0.91(0.34-2.42)$ & $0.91(0.18-4.56)$ \\
\hline $19-24$ & $1.24(0.82-1.89)$ & $1.54(0.73-3.24)$ & $1.44(0.90-2.32)$ & $1.13(0.66-1.92)$ \\
\hline 31-34 years & $0.94(0.60-1.45)$ & $1.16(0.56-2.41)$ & $1.06(0.63-1.77)$ & $1.26(0.72-2.20)$ \\
\hline $35+$ years & $0.70(0.45-1.10)$ & $0.59(0.28-1.23)$ & $0.78(0.46-1.32)$ & $1.03(0.59-1.80)$ \\
\hline \multicolumn{5}{|c|}{ Australian Indigenous status (Reference: Non Indigenous) } \\
\hline Indigenous & $0.53(0.27-1.04)$ & $0.45(0.14-1.52)$ & $0.83(0.41-1.71)$ & $0.55(0.25-1.19)$ \\
\hline \multicolumn{5}{|c|}{ Socioeconomic status (Reference: Highest ranked 20\%) } \\
\hline Middle ranked $60 \%$ & $0.71(0.45-1.14)$ & $0.78(0.33-1.82)$ & $1.24(0.68-2.26)$ & $1.00(0.53-1.90)$ \\
\hline Lowest ranked $20 \%$ & $0.58(0.32-1.03)$ & $0.59(0.22-1.60)$ & $1.35(0.67-2.75)$ & $0.81(0.38-1.73)$ \\
\hline \multicolumn{5}{|c|}{ Primigravidity (Reference: No) } \\
\hline 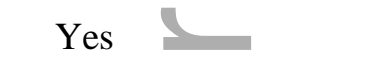 & $1.14(0.80-1.63)$ & $1.02(0.56-1.86)$ & $1.45(0.97-2.17)$ & $1.74(1.13-2.68)$ \\
\hline \multicolumn{5}{|c|}{ Antepartum haemorrhage (Reference: No) } \\
\hline Yes & $1.26(0.81-1.94)$ & $0.53(0.27-1.86)$ & $0.70(0.45-1.09)$ & $0.59(0.31-1.13)$ \\
\hline \multicolumn{5}{|c|}{ Small for gestational age (Reference: No) } \\
\hline Yes & $1.50(1.06-2.11)$ & $1.55(0.90-2.67)$ & $0.84(0.57-1.23)$ & $1.13(0.73-1.75)$ \\
\hline \multicolumn{5}{|c|}{ Unexplained fetal death (Reference: No) } \\
\hline Yes & $0.86(0.56-1.34)$ & $0.71(0.39-1.30)$ & $0.63(0.42-0.93)$ & $0.53(0.35-0.81)$ \\
\hline \multicolumn{5}{|c|}{ Congenital abnormality (Reference: No) } \\
\hline Yes & $1.62(1.12-2.35)$ & $0.99(0.51-1.94)$ & $1.10(0.70-1.73)$ & $2.90(1.61-5.22)$ \\
\hline
\end{tabular}

This article is protected by copyright. All rights reserved 


\begin{tabular}{|c|c|c|c|c|}
\hline \multirow[b]{2}{*}{ Characteristics } & \multicolumn{4}{|c|}{ Adjusted odds ratios $(99 \% \text { confidence interval })^{\S}$} \\
\hline & $\begin{array}{c}<24 \text { weeks } \\
(n=1547)\end{array}$ & $\begin{array}{c}\text { 24-27 weeks } \\
(n=497)\end{array}$ & $\begin{array}{c}\text { 28-36 weeks } \\
\qquad(n=948)\end{array}$ & $\begin{array}{c}\geq 37 \text { weeks } \\
\quad(n=838)\end{array}$ \\
\hline \multicolumn{5}{|c|}{ Type of stillbirth (Reference: Antepartum) } \\
\hline Intrapartum & $0.63(0.43-0.94)$ & $0.37(0.14-1.00)$ & $0.37(0.14-0.98)$ & $1.03(0.53-2.03)$ \\
\hline Unknown & $0.60(0.39-0.91)$ & $0.20(0.05-0.78)$ & $0.60(0.25-1.42)$ & $0.77(0.38-1.55)$ \\
\hline \multicolumn{5}{|c|}{ Remoteness (Reference: Major City) } \\
\hline Regional & $0.95(0.68-1.34)$ & $0.78(0.44-1.37)$ & $0.90(0.61-1.34)$ & $0.90(0.59-1.38)$ \\
\hline Remote & $1.77(0.78-4.03)$ & $0.65(0.15-2.75)$ & $0.94(0.35-2.53)$ & $0.32(0.09-1.19)$ \\
\hline \multicolumn{5}{|c|}{ Epoch (Reference: 2000-2002) } \\
\hline $2003-2005$ & $0.57(0.35-0.94)$ & $0.70(0.30-1.68)$ & $0.77(0.45-1.32)$ & $0.59(0.33-1.05)$ \\
\hline $2006-2008$ & $0.86(0.55-1.35)$ & $1.36(0.58-3.18)$ & $0.90(0.53-1.52)$ & $1.02(0.57-1.81)$ \\
\hline 2009-2011 & $0.84(0.54-1.32)$ & $1.57(0.71-3.47)$ & $1.26(0.75-2.12)$ & $0.91(0.52-1.60)$ \\
\hline
\end{tabular}

${ }^{\S}$ Odds of autopsy relative to no autopsy. Multivariate logistic model adjusted for maternal age, Indigenous status, socioeconomic status, gravidity, presence of antepartum haemorrhage, small for gestational age, initially unexplained fetal death, congenital abnormality, type of stillbirth, remoteness and study period (epoch).

This article is protected by copyright. All rights reserved 


\section{University Library}

\section{- M M N E R VA A gateway to Melbourne's research publications}

Minerva Access is the Institutional Repository of The University of Melbourne

Author/s:

Ibiebele, I;Boyle, FM;Horey, D;Lourie, R;Wilson, P;Coory, M;Flenady, V

Title:

Predictors of autopsy following stillbirth in Queensland, Australia: A population-based study

Date:

2017-02-01

Citation:

Ibiebele, I., Boyle, F. M., Horey, D., Lourie, R., Wilson, P., Coory, M. \& Flenady, V. (2017).

Predictors of autopsy following stillbirth in Queensland, Australia: A population-based study. AUSTRALIAN \& NEW ZEALAND JOURNAL OF OBSTETRICS \& GYNAECOLOGY, 57 (1), pp.33-39. https://doi.org/10.1111/ajo. 12563.

Persistent Link:

http://hdl.handle.net/11343/292119 